\title{
Metallic Fuel Performance Code Requirements for the Versatile Test Reactor Project
}

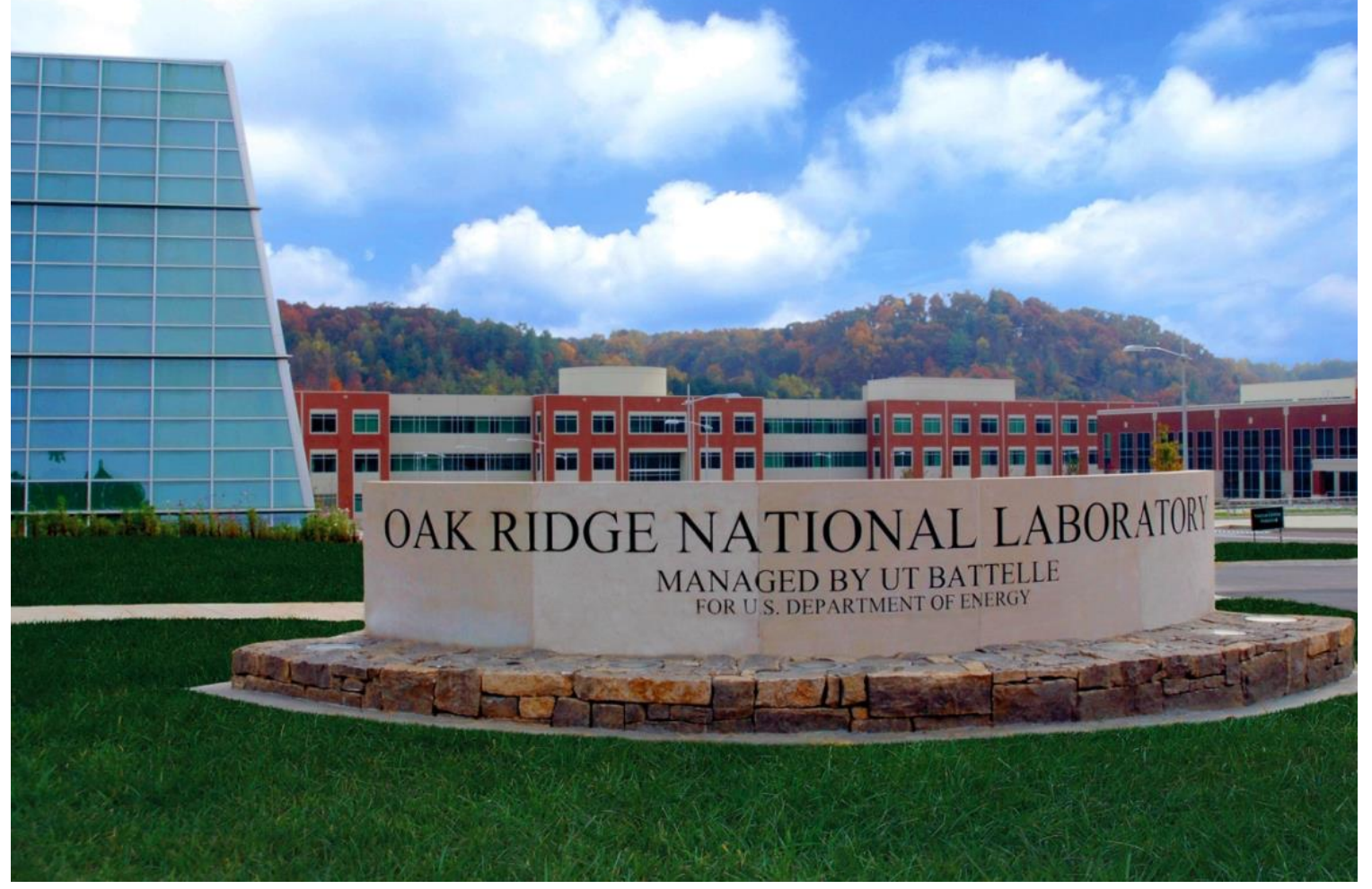

Jacob A. Hirschhorn

Ryan T. Sweet

Jeffrey J. Powers

June 2021

Approved for public release.

Distribution is unlimited. 


\title{
DOCUMENT AVAILABILITY
}

Reports produced after January 1, 1996, are generally available free via US Department of Energy (DOE) SciTech Connect.

Website www.osti.gov

Reports produced before January 1,1996, may be purchased by members of the public from the following source:

\author{
National Technical Information Service \\ 5285 Port Royal Road \\ Springfield, VA 22161 \\ Telephone 703-605-6000 (1-800-553-6847) \\ TDD 703-487-4639 \\ Fax 703-605-6900 \\ E-mail info@ntis.gov \\ Website http://classic.ntis.gov/
}

Reports are available to DOE employees, DOE contractors, Energy Technology Data Exchange representatives, and International Nuclear Information System representatives from the following source:

Office of Scientific and Technical Information

PO Box 62

Oak Ridge, TN 37831

Telephone 865-576-8401

Fax 865-576-5728

E-mail reports@osti.gov

Website https://www.osti.gov/

This report was prepared as an account of work sponsored by an agency of the United States Government. Neither the United States Government nor any agency thereof, nor any of their employees, makes any warranty, express or implied, or assumes any legal liability or responsibility for the accuracy, completeness, or usefulness of any information, apparatus, product, or process disclosed, or represents that its use would not infringe privately owned rights. Reference herein to any specific commercial product, process, or service by trade name, trademark, manufacturer, or otherwise, does not necessarily constitute or imply its endorsement, recommendation, or favoring by the United States Government or any agency thereof. The views and opinions of authors expressed herein do not necessarily state or reflect those of the United States Government or any agency thereof. 
Nuclear Energy and Fuel Cycle Division

\title{
METALLIC FUEL PERFORMANCE CODE REQUIREMENTS FOR THE VERSATILE TEST REACTOR PROJECT
}

\author{
Jacob A. Hirschhorn \\ Ryan T. Sweet \\ Jeffrey J. Powers
}

June 2021

\author{
Prepared by \\ OAK RIDGE NATIONAL LABORATORY \\ Oak Ridge, TN 37831-6283 \\ managed by \\ UT-BATTELLE, LLC \\ for the \\ US DEPARTMENT OF ENERGY \\ under contract DE-AC05-00OR22725
}





\section{CONTENTS}

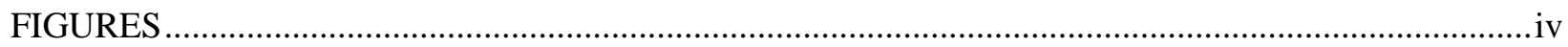

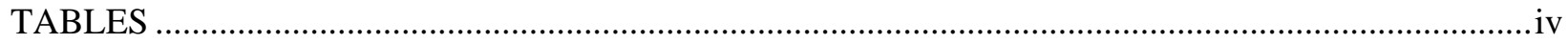

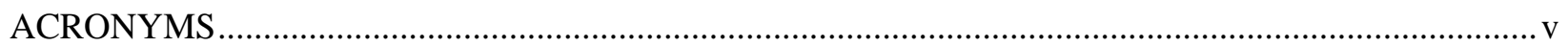

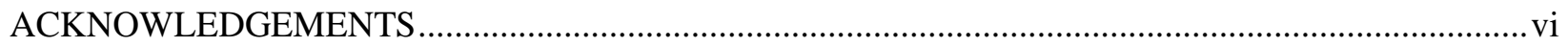

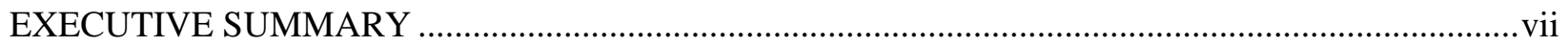

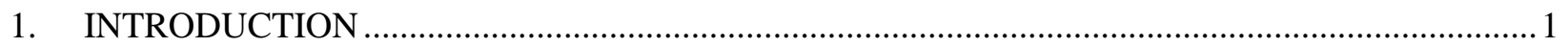

2. ANATOMY OF A REPRESENTATIVE METALLIC FUEL ELEMENT …..................................

3. METALLIC FUEL ELEMENT REQUIREMENTS AND DESIGN CRITERIA ................................

3.1 FUEL ELEMENT DESIGN FUNCTIONAL AND OPERATIONAL

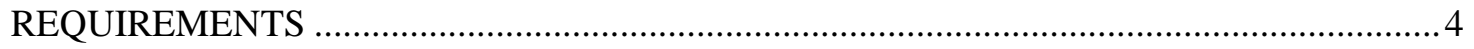

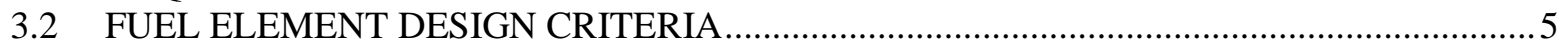

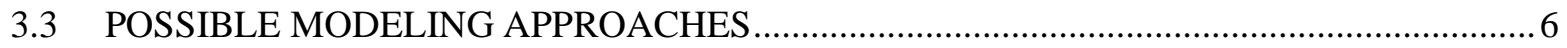

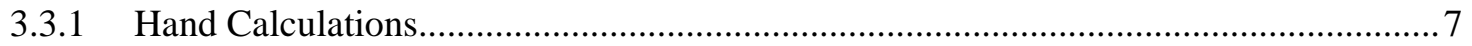

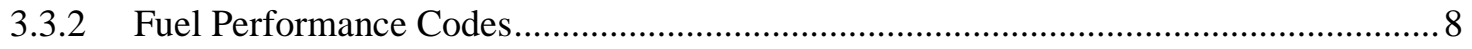

4. METALLIC FUEL BEHAVIOR AND PERFORMANCE ........................................................

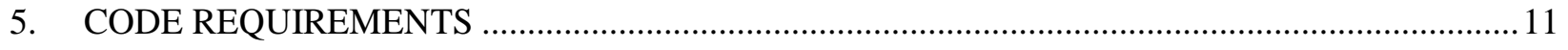

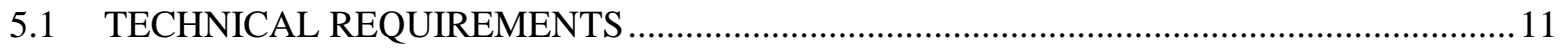

5.1.1 Behaviors and Parameters to be Modeled by a Code .................................................. 11

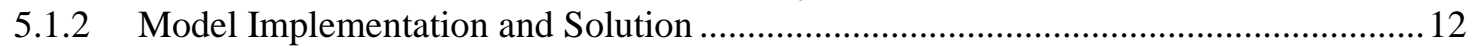

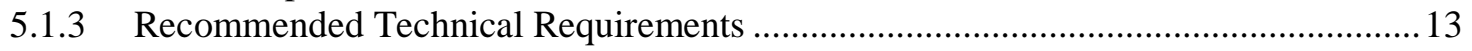

5.2 PROGRAMMATIC AND LOGISTICAL REQUIREMENTS ....................................... 14

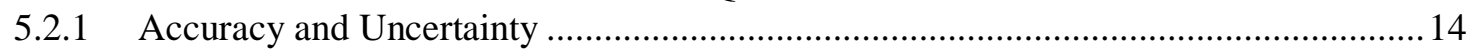

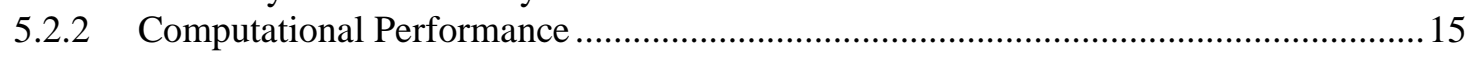

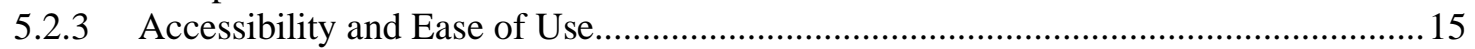

5.2.4 Recommended Programmatic and Logistical Requirements ...................................... 15

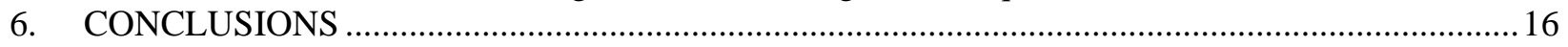

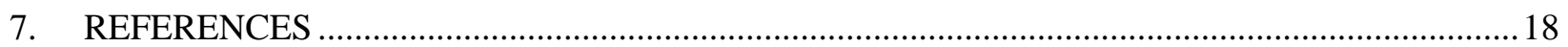




\section{FIGURES}

Figure 1. Schematic cross sectional drawing illustrating the various components of a metallic fuel element (the top of the fuel element is to the right; components are not shown to scale).

\section{TABLES}

Table 1. The design criteria established for EBR-II Mark-V fuel elements and the operating conditions to which they apply [32] ...

Table 2. Composition and dimensions of an example metallic fuel element based on the reference design parameters recommended by Crawford et al. [26]

Table 3. Summary of selected technical code requirements.... 


\section{ACRONYMS}

$\begin{array}{ll}\text { ASME } & \text { American Society of Mechanical Engineers } \\ \text { CDF } & \text { cumulative damage fraction } \\ \text { EBR-II } & \text { Experimental Breeder Reactor II } \\ \text { FCCI } & \text { fuel-cladding chemical interaction } \\ \text { FCMI } & \text { fuel-cladding mechanical interaction } \\ \text { FFTF } & \text { Fast Flux Test Facility } \\ \text { FGR } & \text { fission gas release } \\ \text { IFR } & \text { Integral Fast Reactor } \\ \text { LWR } & \text { light-water reactor } \\ \text { NQA-1 } & \text { Nuclear Quality Assurance-1 } \\ \text { NRC } & \text { US Nuclear Regulatory Commission } \\ \text { PIE } & \text { post-irradiation examination } \\ \text { SFR } & \text { sodium-cooled fast reactor } \\ \text { SS316 } & \text { stainless steel 316 } \\ \text { TREAT } & \text { Transient Reactor Test Facility } \\ \text { VTR } & \text { Virtual Test Reactor }\end{array}$




\section{ACKNOWLEDGEMENTS}

This work is the result of ongoing efforts supporting the Versatile Test Reactor project and was sponsored by the US Department of Energy Office of Nuclear Energy. The authors would like to acknowledge Ian Greenquist and Jianwei Hu of Oak Ridge National Laboratory, Douglas Crawford and Douglas Porter of Idaho National Laboratory, and Aydin Karahan and Lander Ibarra of Argonne National Laboratory for their constructive technical and editorial feedback. 


\section{EXECUTIVE SUMMARY}

Metallic nuclear fuels have been proposed for use in several emerging nuclear reactor designs, and a number of codes have been developed to model these fuels and assess their performance. Qualification of these metallic nuclear fuels will ultimately require monitored irradiation of lead test assemblies, but the use of fuel performance codes can reduce the uncertainty associated with these efforts by quantifying uncertainties and estimating margins to failure ahead of time. In this work, metallic fuel performance code requirements are defined for the Versatile Test Reactor (VTR) project using input from the Experimental Breeder Reactor II functional requirements, operational requirements, and design criteria. This work focuses on the thermomechanical responses and irradiation behaviors of metallic fuel elements that are representative of the proposed VTR driver fuel design concepts. As such, many of the code requirements and physics/modeling discussions in this work are expected to be broadly applicable to metallic fuel applications outside of the VTR project.

Minimum technical code requirements were defined first. These requirements ensure that the code has the capabilities needed to simulate the coupled thermomechanical fuel and cladding behaviors that impact fuel performance and safety. In general, the minimum requirements dictate that the code must be able to calculate values associated with fuel performance conditions and behaviors such as (1) fuel, cladding, and coolant temperature, (2) fuel and cladding strain, including the effects of thermal expansion, swelling, and creep, and (3) cladding stress, including the effects of internal fission gas pressure, fuel-cladding mechanical interaction, and chemical reaction-induced wastage. Additional desired features were outlined next. These features emphasize a higher degree of spatial resolution and address advanced models and concepts such as cladding failure probability, constituent redistribution, and code coupling capabilities. These features are expected to improve the fidelity and utility of code predictions.

Programmatic and logistical issues that are likely to impact fuel performance code development, selection, and use were then examined. These issues relate to (1) acceptable levels of accuracy and uncertainty in code predictions, (2) use of benchmarking, code comparisons, and uncertainty quantification, (3) the availability of stable code versions, (4) quality control and assurance, (5) computational performance and scalability, (6) controls and restrictions associated with proprietary and export controlled information, (7) the availability of training and documentation for new and experienced users, (8) compatibility with various operating systems, postprocessing tools, and irradiation experiment databases, and (9) other cost, quality, and security concerns. These requirements will inform the benchmarking plan which is to be prepared later in 2021 for the VTR project. In the benchmarking plan, the selected metallic fuel performance code will be evaluated against the technical code requirements presented in this document to identify potential shortcomings and to inform recommendations for further development. The logistical and programmatic code requirements will continue to be refined as necessary and appropriate in collaboration with VTR leadership, members of the VTR quality team, and others. 


\section{INTRODUCTION}

Metallic nuclear fuels have been proposed for use in a number of emerging reactor designs, including several reactors currently under development by private industry [1]-[3]. The US Department of Energy Office of Nuclear Energy is also planning to construct a new fast-spectrum test reactor called the Versatile Test Reactor (VTR) [4]. The materials to be used for these new reactor designs offer passive safety characteristics. For example, proposed coolants have high boiling points and high heat transfer capabilities, and the metallic fuel has favorable reactivity feedback behavior, high burnup potential ( $>20$ atom percent [at. \%]), and high ${ }^{238} \mathrm{U}$ usage. These features also make the materials attractive for commercial energy production [5]. Additionally, the metallic fuels can supply fast neutron fluxes, which makes them desirable for material testing and degradation studies [6]. Despite these advantages, metallic fuels have not yet been deployed extensively in commercial nuclear operations.

The US nuclear community has extensive non-commercial experience with $\mathrm{U}-\mathrm{Zr}$ and $\mathrm{U}-\mathrm{Pu}-\mathrm{Zr}$ metallic fuels in sodium-cooled fast reactors (SFRs). Tens-of-thousands of metallic fuel elements were irradiated in Experimental Breeder Reactor II (EBR-II), including those during the Integral Fast Reactor (IFR) program of the 1980s and 1990s [7]. These developments and design evolutions were responsible for numerous major design and material improvements, thus establishing the foundation for current metallic fuel element designs [8], [9]. Irradiation experiments were also conducted at the Fast Flux Test Facility (FFTF) [10] and the Transient Reactor Test Facility (TREAT) [11], and numerous other supporting scientific and engineering studies characterized the properties and performance of metallic fuels.

During operation, metallic nuclear fuel rods undergo fundamental material changes in response to the temperature, loading, chemical, and irradiation conditions within the reactor. To meet specific safety criteria, the significant changes that pose a risk to the fuel rod integrity or reactor control must be assessed. Approaches for calculating the impact of these phenomena vary based on the desired degree of accuracy and the available data. Due to the complex reactor environment, some fuel performance code developers recommend a coupled multiphysics approach to determine integral fuel behavior under representative conditions. This approach evaluates all phenomenological models simultaneously to obtain a more realistic calculation. However, as more coupled models are introduced, the process quickly becomes more difficult and computationally demanding. For faster and simpler approximations, hand calculations with engineering assumptions may be used.

A number of codes have been developed in the United States and elsewhere to assess metallic fuels against performance metrics and safety criteria, including LIFE-METAL [12], [13], SESAME [14], ALFUS [15], MACSIS [16], FEAST-METAL [17], FAST [18], BISON [19], [20], and SAS4A [21]-[23]. These codes have been applied to aid in fuel element design, performance, and safety calculations; plan and interpret the results of irradiation experiments; and support fuel qualification efforts. Each code was developed under unique circumstances, and their implementations and predictive capabilities vary. While the benchmarking results available in the open literature for these codes seem promising, code documentation and access to the codes themselves are somewhat limited.

Use of fuel performance codes throughout the fuel design and qualification processes could mitigate some of the costs and logistical constraints by providing greater understanding of operation and safety margins. While fuel qualification will ultimately require irradiation and monitoring of lead test assemblies, the use of fuel performance codes can reduce the uncertainty associated with these efforts by quantifying specific uncertainties and estimating margins-to-failure ahead of time. As such, new reactor development will likely rely on a combination of IFR-era designs and the safety and performance analyses obtained from fuel performance codes. The purpose of this work is to define the requirements for a metallic fuel performance code for the VTR project. These requirements are intended to help code developers prioritize further work, establish and maintain quality programs, and compile relevant and comprehensive 
performance benchmarks. The requirements will also help researchers and engineers evaluate the applicability, reliability, and limitations of the codes available to them. Finally, the requirements will help planners and program managers to coordinate these efforts.

First, the structure and geometry of metallic fuel elements and the materials commonly used in their construction are reviewed. IFR-era functional requirements, operational requirements, and design criteria are then examined. Metallic fuel thermomechanical responses and irradiation behaviors are then reviewed to identify general expectations for fuel performance codes. Finally, the technical, programmatic, and logistical concerns associated with the use of fuel performance codes are examined, and recommendations for applying codes to support development of new reactors are provided.

\section{ANATOMY OF A REPRESENTATIVE METALLIC FUEL ELEMENT}

In this section, the components of a metallic fuel element representative of the proposed VTR driver fuel design concepts are identified to establish common terminology and to provide context for the discussions that follow [24]. Since the 1950s, experiments have been conducted using numerous types of metallic fuels, including pure $\mathrm{U}$ and $\mathrm{Pu}$ metals, binary alloys such as $\mathrm{U}-\mathrm{Zr}, \mathrm{Pu}-\mathrm{Al}, \mathrm{U}-\mathrm{Cr}, \mathrm{U}-\mathrm{Mo}$, and mixed alloy fuels such as U-Pu-Zr and U-Fs* [25]. Various cladding materials and fuel geometries were also explored [5], [26], [27]. This work focuses on designs and materials from EBR-II during the final stages of the IFR program. Specifically, this work focuses on the EBR-II Mark-V and Mark-VA fuel designs, which were not deployed before EBR-II was shut down in 1994, but nevertheless, they embodied the knowledge about $\mathrm{U}-\mathrm{Zr}$ and $\mathrm{U}-\mathrm{Pu}-\mathrm{Zr}$ fuel at the time. These designs and materials were selected for the present work because their successful development and use at EBR-II and the wealth of operational data available for them make them strong candidates for use in new SFRs.

This work considers (1) U-Pu-Zr fuel alloys with Pu contents between 0 and $20 \%{ }^{\dagger}$, (2) ferritic-martensitic HT-9, austenitic D9, and austenitic stainless steel 316 (SS316) cladding alloys, (3) fuel element geometries with smeared densities ${ }^{\ddagger}$ of approximately $75 \%$, and (4) fuel elements that utilize a liquid sodium bond. Non Zr-based metallic fuels and other fuels not intended for use in SFRs are not considered. Multiple cladding materials that were used in the irradiation experiments are considered, as they should likely be simulated to benchmark a metallic fuel performance code. While some aspects of the EBR-II designs, such as fuel element dimensions, are expected to be different for specific reactor designs, the features listed above are believed to represent the majority of new metallic fuel elements - at least those being discussed for near-term deployment. A schematic drawing illustrating the various components of a metallic fuel element is shown in Figure 1.

\footnotetext{
${ }^{*} \mathrm{~A}$ mixture of $\mathrm{Mo}, \mathrm{Ru}, \mathrm{Tc}, \mathrm{Pd}, \mathrm{Zr}$, and $\mathrm{Nb}$ fission products, collectively referred to as fissium.

${ }^{\dagger}$ All compositions in this work are expressed in weight-percent unless otherwise noted.

tRatio of the cross sectional area of the as-fabricated fuel to the inner cross sectional area of the as-fabricated cladding.
} 


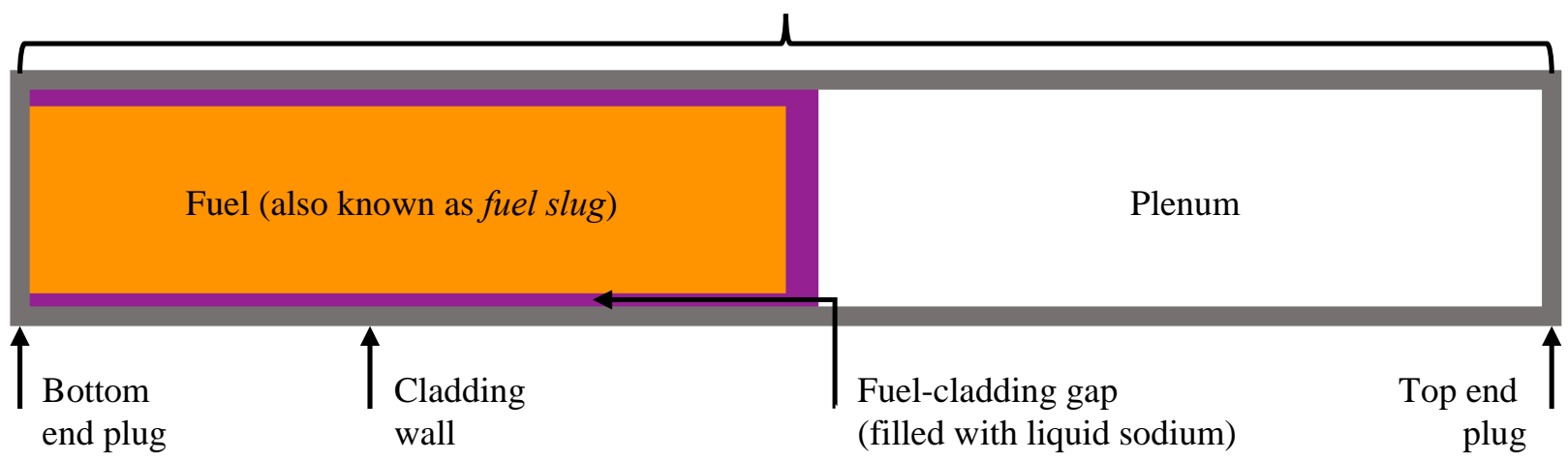

Figure 1. Schematic cross sectional drawing illustrating the various components of a metallic fuel element (the top of the fuel element is to the right; components are not shown to scale).

Several major changes have been proposed in some fast reactor fuel designs, including the use of extruded annular fuels, which do not require sodium bonds [28], and inclusion of fuel-cladding diffusion barriers to help mitigate fuel-cladding chemical interaction (FCCI) [29]. Some of the discussions in this work may be applicable to those new designs, but the designs are not specifically addressed herein because they may require additional or modified fuel performance code requirements.

\section{METALLIC FUEL ELEMENT REQUIREMENTS AND DESIGN CRITERIA}

The US Nuclear Regulatory Commission (NRC) establishes general design criteria for nuclear power plants in the US Code of Federal Regulations [30]. These criteria were based primarily on light-water reactor (LWR) technology. To facilitate design and licensing of advanced reactor concepts (including SFRs), the NRC recently released guidance for developing principal design criteria for non-LWRs [31]. This guidance is intended to serve as a modification and to supplement the existing general design criteria for different reactor technologies, but the underlying safety objectives remain the same. Criteria relevant to this work relate to containment of radioactive nuclides, reactivity control, cooling, fuel handling and storage, quality standards, and recordkeeping. These general criteria are used to define functional requirements, operational requirements, and more specific fuel element design criteria.

This section reviews and discusses the safety analyses and technical justifications that were used to inform requirements and design criteria for the EBR-II Mark-V and Mark-VA fuel subassemblies [32]. These studies were chosen because they represent the most recent application of metallic fuel to an operating reactor and because most of the associated information is publicly available, unlike information about proprietary applications of metallic fuel to new commercial reactor designs. Even though these studies may not reflect all of the recent advances in metallic fuel understanding and qualification practices, they do establish a convenient baseline for designating the indicators of fuel element behavior that are important to model and predict. With this baseline, contemporary, project-specific code requirements can be developed.

The Mark-V and Mark-VA designs used $~ 34 \mathrm{~cm}$ long U-20Pu-10Zr fuel slugs clad with HT-9 and 20\% cold-worked SS316, respectively. The fuel slug diameters were varied to accommodate differences in cladding thicknesses while preserving a smeared density of $75 \%$, and an interim burnup limit was set at 10 at. $\%$. These fuel design choices were influenced by (1) the objective to demonstrate closure of the fuel cycle through the use of fuel produced in the Fuel Cycle Facility (hot cell), and (2) the idea that burnup limits could be raised later if or when experimental data demonstrated acceptable performance and safety. 
Even though fuel element dimensions, materials, and minor design features may differ among the reactor types and purposes, there are enough similarities in their overall designs and irradiation behaviors to allow for initial, general discussion of their requirements and design criteria. Throughout this work, discussions that are broadly applicable to many fuel element designs are distinguished from those that are specific to a particular material or design feature.

\subsection{FUEL ELEMENT DESIGN FUNCTIONAL AND OPERATIONAL REQUIREMENTS}

The functional requirements established for the Mark-V and Mark-VA fuel subassemblies included producing heat and transferring it to the coolant, positioning fissile material for reactivity control and cooling, containing radioactive isotopes, and facilitating fuel handling and core reload. Specifically, fuel elements should [33]

- position fissile material in the reactor core in a stable, predictable manner to allow for a controlled fission reaction,

- allow for effective transfer of nuclear reaction heat from the fuel to the coolant (or heat transfer medium),

- provide containment of radionuclides (fuel and fission products) for operational convenience and as a first barrier for safety, and

- provide/allow for a convenient means of loading fresh fuel into the core and removing and managing spent fuel.

Design criteria are defined to limit or prevent processes that impede a fuel element's ability to satisfy these qualitative requirements. Quantitative limits for measurable or calculable parameters are established when possible so that compliance with the criteria can be assessed under various operating conditions. Generally, the processes of concern are changes to the fuel geometry such as cladding deformation and cladding rupture. Cladding deformation may impede coolant flow and could lead to mechanical interference with other core components, which can make fuel handling and core reload more difficult. Cladding rupture releases radioactive fission products into the coolant, and depending on the fuel temperature, it may also release molten fuel into the coolant, further disrupting coolant flow. Bulk fuel melting can also result in fuel material relocation within the fuel rods and undesirable changes in reactivity. How well a fuel design maintains the fuel and fission products in a known geometry and prevents release to the coolant is a key consideration for some source-term estimates in safety calculations, so it is a fundamental requirement under most known SFR safety bases.

Cladding wastage results from chemical interactions and diffusive processes, reducing the cladding's effective thickness and load-carrying capacity [34]. These processes are collectively referred to as fuelcladding chemical interaction (FCCI) and may include depletion of $\mathrm{Ni}$ and/or $\mathrm{C}$ in the cladding, as well as formation of brittle, lanthanide-based phases. FCCI also causes accumulation of a U-Fe eutectic or eutectic-like phase at the fuel-cladding interface. The low melting temperature of the phase makes localized melting more likely and can further degrade cladding integrity through a process referred to as eutectic liquefaction. These processes are detailed further in Section 4.

The operational requirements that were established for the Mark-V and Mark-VA fuel subassemblies defined the expectations for their power levels, duty cycles (in terms of burnup or neutron fluence), and performance during various design basis events, including normal operation and off-normal events. Offnormal events include anticipated, unlikely, and extremely unlikely events such as loss of flow or 
reactivity insertion. Although power levels and duty cycles will differ, these types of requirements and design-basis events are generally applicable to other metallic fuel element designs.

\subsection{FUEL ELEMENT DESIGN CRITERIA}

The preceding section describes the requirements that a fuel element design must satisfy and the phenomena that impede the ability to do so. Specific design criteria are established to ensure that the effects of these in-service phenomena remain within the expected bounds. The design criteria established for EBR-II Mark-V fuel elements are summarized and categorized by the likelihood of occurrence in Error! Reference source not found. [32] below. This section examines the objectives of these criteria a nd the methods used to monitor and enforce them, as well as recommendations on how they can be generalized to a broader subset of metallic fuel element designs.

Table 1. The design criteria established for EBR-II Mark-V fuel elements and the operating conditions to which they apply [32]

\begin{tabular}{|c|c|c|c|c|c|}
\hline & Design Criterion & $\begin{array}{c}\text { Normal } \\
\text { operation }\end{array}$ & $\begin{array}{l}\text { Anticipated } \\
\text { events }\end{array}$ & $\begin{array}{l}\text { Unlikely } \\
\text { events }\end{array}$ & $\begin{array}{l}\text { Extremely } \\
\text { unlikely } \\
\text { events }\end{array}$ \\
\hline 1.1 & $\begin{array}{l}\text { The thermal component of the plastic diametrical } \\
\text { strain for the cladding shall be less than } 1 \% \text {. }\end{array}$ & $\checkmark$ & & & \\
\hline 1.2 & $\begin{array}{l}\text { The cumulative damage fraction (CDF) for the } \\
\text { cladding shall be limited to } 0.05 \text {. }\end{array}$ & $\checkmark$ & & & \\
\hline 1.3 & $\begin{array}{l}\text { The power in the hottest fuel pin shall be less than } \\
\text { the minimum value for incipient bulk fuel melting. }\end{array}$ & $\checkmark$ & $\checkmark$ & $\checkmark$ & \\
\hline 1.4 & $\begin{array}{l}\text { The power-to-flow ratio and the power in the } \\
\text { hottest fuel pin shall be less than the minimum } \\
\text { value for macroscopic eutectic liquefaction at the } \\
\text { fuel-cladding interface. }\end{array}$ & $\checkmark$ & & & \\
\hline 1.5 & $\begin{array}{l}\text { The plenum pressure shall be less than that which } \\
\text { would cause a peak, radially averaged hoop stress } \\
\text { in the cladding of } 150 \mathrm{MPa} \text { in the hottest fuel pin. }\end{array}$ & $\checkmark$ & & & \\
\hline 1.6 & $\begin{array}{l}\text { The cumulative eutectic penetration of the cladding } \\
\text { shall be less than } 5 \% \text { of the wall thickness. }\end{array}$ & & $\checkmark$ & $\checkmark$ & $\checkmark$ \\
\hline 1.7 & The CDF for the cladding shall be less than 0.1 . & & $\checkmark$ & $\checkmark$ & \\
\hline 1.8 & $\begin{array}{l}\text { The cumulative thermal component of the plastic } \\
\text { diametrical strain for the cladding shall be less } \\
\text { than } 1 \% \text {. }\end{array}$ & & $\checkmark$ & $\checkmark$ & \\
\hline 1.9 & The core shall remain coolable. & $\checkmark$ & $\checkmark$ & $\checkmark$ & $\checkmark$ \\
\hline
\end{tabular}

Many aspects of these design criteria require further discussion. These criteria are determined through a combination of the material limits derived from testing, the safety factors applied to ensure fuel failures remain unlikely, and the functional and operational requirements defined for the fuel. While the purposes of the criteria are rooted in theory, the process by which they are monitored and enforced is a more practical matter. This distinction is important because some quantities can be measured experimentally whereas others can only be predicted using hand calculations and fuel performance codes. For example, Criteria 1.3 and 1.4 are primarily concerned with the temperature of the fuel, which cannot be easily measured in situ. In practice, these criteria are satisfied by enforcing limits on the power and power-toflow ratio, which can be monitored more easily. Note that these criteria implicitly rely, in part, on 
calculations that relate the rates of heat production, transport, and removal, which change over time due to the effects of fission on the fuel structure.

Several of the criteria are either redundant or interrelated. These redundancies are included because (1) multiple processes can contribute to violation of a functional requirement, and (2) different standards are applied during normal operation vs. off-normal events. Likewise, multiple criteria can be specified to establish guidelines for singular requirements. For example, Criteria 1.1, 1.2, and 1.4-1.8 limit behaviors that contribute to cladding rupture, and Criteria 1.1 and 1.8 impose constraints on cladding deformation that can restrict coolant flow (by reducing the available flow area through the fuel rod bundle), can lead to mechanical interference with other core components, or can otherwise indicate accumulating cladding damage. Meanwhile, Criterion 1.6 simultaneously limits reduction of cladding wall thickness by limiting the amount of U-Fe eutectic that can form and contribute to eutectic liquefaction. It would be more straightforward if a fuel element could be assessed based on a one-to-one relationship between its requirements and design criteria. However, the coupled nature of the multiphysics processes involved may make this approach impractical for many applications.

Metallic fuels have multiphase structures at room temperature and during operation, and their phase compositions change during irradiation due to constituent redistribution and other phenomena. Phases with low $\mathrm{Zr}$ content have the lowest melting temperatures. The volume-fractions of these low melting temperature phases vary spatially, depending on the bulk constituent composition and local temperature. Fuel-cladding interdiffusion leading to U-Fe eutectic formation at the fuel-cladding interface and possibly in the fuel itself (observed in out-of-pile tests at elevated temperatures) introduces additional complexities by further reducing melting temperature. Phenomenologically, some incipient melting in a mid-radius low-Zr fuel zone might be acceptable, but Criteria 1.3 and 1.4 can both be satisfied if fuel and eutectic melting are prohibited altogether (neglecting the formation of minor volatile fission products). As such, requiring that local fuel temperature remain below the local solidus temperature (based on the expected local composition after fuel constituent redistribution and fuel-cladding interdiffusion) may be the most generally applicable approach for normal operation. This approach would also help to satisfy Criterion 1.9 by limiting the amount of molten material available that can contribute to flow blockages if the cladding were to rupture, but it may be too restrictive for anticipated, unlikely, and extremely unlikely events.

Cladding materials in this environment are susceptible to fundamental material and microstructural changes such as wastage, irradiation-induced swelling, and thermal and irradiation creep. The fuel cladding is also subject to various loading conditions and deformation in response to internal fission gas pressure and fuel-cladding mechanical interaction (FCMI). These design criteria place limits on the thermal component of the plastic diametrical strain in the cladding, but they do not differentiate between deformation caused by cladding swelling, irradiation creep, and the stress induced by FCMI. These omissions may limit the applicability of the criteria to other fuel element designs and operational conditions, particularly at higher burnups. However, these functional and operational requirements, design criteria, and other observations set a baseline for which indicators of fuel element behavior are important to model and predict.

\subsection{POSSIBLE MODELING APPROACHES}

The ability to accurately and confidently calculate the fuel element behavior indicators identified in the preceding section prior to irradiation of lead test assemblies would add confidence that the fuel design will fulfill its design functions. There are two plausible approaches to predicting fuel performance, separated by varying degrees of accuracy: (1) engineering approximations and hand calculations, and (2) fuel performance codes. The details of each approach are described in the remainder of this section to illustrate their various merits and shortcomings. 


\subsubsection{Hand Calculations}

A simple example of the first approach involves applying the thick- and thin-walled pressure vessel approximations to estimate whether a given fuel element design is likely to withstand certain operational conditions without failure. These techniques can be applied in countless ways: this example is generally illustrative of their advantages and limitations. The example considers a metallic fuel element based on the reference design parameters recommended by Crawford et al. [26], which are listed in Table 2 [32].

Table 2. Composition and dimensions of an example metallic fuel element based on the reference design parameters recommended by Crawford et al. [26]

\begin{tabular}{ll}
\hline \multicolumn{1}{c}{ Fuel element parameter } & \multicolumn{1}{c}{ Value } \\
\hline Fuel type & $\mathrm{U}-20 \mathrm{Pu}-10 \mathrm{Zr}$ \\
Cladding type & $\mathrm{HT}-9$ \\
Fuel length & $91 \mathrm{~cm}$ \\
Fuel radius & $0.25 \mathrm{~cm}$ \\
Cladding thickness & $0.06 \mathrm{~cm}$ \\
Cladding outer radius & $0.345 \mathrm{~cm}$ \\
Total plenum volume at $25^{\circ} \mathrm{C}$ & $25 \mathrm{~cm}^{3}$ \\
Sodium level above fuel (assumed) & $1 \mathrm{~cm}$ \\
\hline
\end{tabular}

Assuming that cladding rupture occurs due to internal fission gas pressure only, the maximum burnup to which the fuel element can be operated while minimizing the risk of cladding rupture can be estimated as follows. The fission gas yield is assumed to be $25 \%$, fission gases are assumed to be immediately and fully vented to the plenum, and the fuel and cladding dimensions are assumed to be independent of temperature and burnup (neither undergo creep nor swelling). Fission gases have been shown to be compressible at typical plenum pressures [35], but the ideal gas approximation is expected to be sufficiently accurate for the purposes of this simple example.

The cladding is assumed to behave like a hollow cylinder of infinite length so that mechanical interactions near its end plugs do not need to be considered. The thin-wall approximation is generally valid when the ratio of the wall's mid-radius $r_{m}$ to its thickness $t$ is about 10 or more. Both the thick- and thin-wall approximations are used for this example because the fuel element's $r_{m} / t$ ratio is about 5.3. Assuming that the pressure outside the cladding is negligible (near-atmospheric), the thick-wall approximation gives the maximum hoop stress in the cladding $\sigma_{h}$, which occurs at its inner surface, as

$$
\sigma_{h}=P \frac{r_{i}^{2}+r_{o}^{2}}{r_{o}^{2}-r_{i}^{2}},
$$

where $P$ is the fission gas pressure, and $r_{i}$ and $r_{o}$ are the inner and outer radii of the cladding, respectively. Similarly, the thin-wall approximation is given as

$$
\sigma_{h}=P \frac{r_{m}}{t}
$$

Using the dimensions from Table 2 in Eqs. (1) and (2) shows that the two approximations differ by only about $1 \%$ in this case, so the simpler thin-wall approximation is sufficient for the remainder of the example. Based on the fuel element dimensions, the fuel and plenum gas volumes are about 17.9 and 24.7 $\mathrm{cm}^{3}$, respectively. Using a fuel density of $15.8 \mathrm{~g} / \mathrm{cm}^{3}$, about 1.06 mols of heavy metals are present in the 
fuel element at startup. Given the assumptions above, this yields approximately $2.65 \times 10^{-3}$ mols of fission gas per atom-percent burnup. (The gas content of the plenum at startup is insignificant because it is argon at sub-atmospheric pressure.) Finally, Eq. (2) can be combined with the ideal gas law to obtain

$$
\sigma_{h}=\frac{n R T}{V} \frac{r_{m}}{t}
$$

where $n$ is the number of mols of fission gas in the plenum (which scales with burnup), $R$ is the ideal gas constant, $T$ is the temperature, and $V$ is the plenum gas volume. At a temperature of $600^{\circ} \mathrm{C}$, this analysis suggests that the fuel element can be operated until about 36 at. \% burnup before the internal fission gas pressure is sufficient to induce a hoop stress in the cladding of $150 \mathrm{MPa}$ (the limit specified for EBR-II Mark-V fuel elements during normal operation). This approach can deliver estimates like these quickly and easily.

Admittedly, this hand calculation is based on a substantial number of simplifying assumptions, not all of which were conservative. A safety factor could be applied when assessing the margin to the $150 \mathrm{MPa}$ limit, but a basis for the safety factor value would need to be developed. This analysis suggests that cladding rupture would not be a concern for fuels operated up to 20 at. \% burnup (which is supported by results of irradiation testing in EBR-II and FFTF), but the effects of FCMI and FCCI were not explicitly addressed in the simpler calculation. Therefore, this hoop stress calculation alone may not be sufficient to demonstrate satisfactory performance with respect to the fuel element design criteria.

Accounting for these additional considerations within this simpler approach would become increasingly complex and difficult to perform and defend. Accurate prediction would also require applicable fuel and cladding temperatures to be calculated (rather than assuming a conservatively high temperature), as well as the fuel and cladding strains due to thermal expansion, creep, swelling, and the likelihood of cladding failure. Correlations could be applied to conservatively predict some of these quantities, but without more assumptions and simplifications or more sophisticated calculation techniques, coupled effects would be missed. Based on these factors, this approach may be best suited for preliminary estimates and scoping calculations, as well as straightforward confirmatory calculations.

\subsubsection{Fuel Performance Codes}

The second approach uses fuel performance codes to predict the integral thermomechanical response of the fuel element. The codes solve partial differential heat generation/transport and stress divergence equations to directly calculate temperature, stress, and strain throughout the fuel element. Materialspecific correlations are used to define properties such as thermal conductivities, specific heat capacities, thermal expansion coefficients, and elastic moduli. Behavioral models are employed to account for irradiation and other effects such as porosity development, swelling, fission gas release (FGR), creep, and cladding wastage and damage.

Fuel performance codes offer designers higher resolution information, but these improvements have a cost. Depending on the code used, calculations can be computationally expensive, requiring hours or days to run on high performance computing clusters. In this scenario, new users must overcome steep learning curves, and experienced code developers trained in both nuclear engineering and computer science must be kept on staff to maintain and update the codes.

As with the example here, the accuracy and reliability of results obtained from fuel performance codes depends strongly on the accuracy of the models of fuel phenomena, the quality of input parameters, and the validity of the assumptions and simplifications employed. Publicly available documentation and benchmarking studies suggest that existing codes are at least as reliable as hand calculations, but the 
sparsity of this vital supporting documentation makes it difficult to claim that any of the codes contain the tools necessary to accurately predict the behavior of all the relevant fuel and cladding materials under all operating conditions of interest.

Their current limitations notwithstanding, these codes are valued because they account for the coupled effects of various thermomechanical and irradiation behaviors, and they also provide additional insight into fuel element behaviors that are not easily observed in experiments. Using fuel performance codes to assess the behavior of oxide fuels is ubiquitous and has provided confidence in the prediction of oxide fuel performance under design-basis conditions, particularly for LWRs. Based on these factors, a similar deployment for metallic fuels is envisioned. The following sections review metallic fuel behaviors in greater detail and define the code requirements necessary to implement this approach.

\section{METALLIC FUEL BEHAVIOR AND PERFORMANCE}

This section provides a more thorough review of the physical processes that influence fuel temperature, and strain, as well as cladding temperature, strain, stress, wastage, and damage. The individual contributions to each of these quantities are examined, and attention is drawn to significant differences between the responses of the various fuel and cladding materials. The content is focused on experimental observations and the theories established to explain them. Practical details related to modeling the observed behaviors and how those models should be implemented in a fuel performance code are discussed in Section 5.

The integral performance of a metallic fuel element is a function of its thermomechanical response to a condition that changes over time in service, including degradation of cladding properties, accumulation and effects of fission products, and interdiffusion and migration of fuel and cladding constituents and fission products. Thermomechanical responses are modeled using equations such as heat generation/transport and stress divergence. These modeling techniques account for phenomena such as heat conduction, thermal expansion, elasticity, plasticity, and thermal and mechanical contact; however, the techniques are common to many engineering applications. They have been successfully applied for decades to predict the behavior of metallic and oxide fuels [18], [36].

Behaviors associated with reactor operation add to the complexity of modeling nuclear fuel. These behaviors are induced by the interaction of neutrons and fission fragments with the material. Irradiation behaviors involve processes such as irradiation-induced swelling (void swelling in the cladding and fission product-driven swelling in the fuel) and irradiation creep; these behaviors vary with material and operational conditions. The irradiation behaviors of concern are gaseous and solid swelling in the fuel, porosity formation and evolution in the fuel, FCMI, FGR, irradiation creep in the fuel and cladding, irradiation-induced swelling and embrittlement in the cladding, FCCI, and constituent redistribution in the fuel. These behaviors are responsible for fuel and cladding deformation and can influence changes in material properties such as thermal conductivities and elastic moduli. Each behavior is discussed in further detail below, and more in-depth reviews are available in the open literature [9], [34], [37], [38].

When a fresh metallic fuel element is irradiated in a reactor, gaseous and solid fission products begin to accumulate within the fuel lattice, causing it to swell [39]. The gaseous fission products accumulate and form pores or bubbles, which eventually grow to interconnect as channels that allow fission gases to migrate toward the surface of the fuel. Fission gases (roughly 70 to $80 \%$ of those generated) are ultimately released into the fuel element plenum, where they increase the pressure and contribute to cladding hoop stress. The interconnected pores continue to vent new gaseous fission products to the plenum, limiting additional gaseous swelling. Fuel swelling is essentially constant from the onset of FGR to about 10 at. \% burnup [40]. During this time, new solid fission products are accommodated by growth 
into the fuel porosity. Experimental results from EBR-II suggest that FGR may vary with Pu content, but the data are too limited and scattered to make a conclusive judgement [9].

Fuel swelling can affect core reactivity, and axial elongation is a particular concern due to the high aspect ratio of the fuel. The binary fuels irradiated in EBR-II generally exhibited greater swelling and axial elongation than the ternary fuels [41], [42]. Differences in the fuels' swelling behaviors may be due to differences in their crystalline structure and creep rates. However, no generally applicable theories or models capable of explaining these phenomena have been put forward. Swelling is generally agreed to be anisotropic in the low-temperature phases [39], but the available experimental data are insufficient to describe the swelling behavior of the stable multiphase mixtures that are dispersed throughout these fuels. Prediction of axial fuel swelling is further complicated by the effect of fuel-cladding contact and its presumed contribution to resisting axial elongation of the fuel column.

Excessive radial fuel swelling in conjunction with thermal expansion produces contact between the fuel and cladding, causing FCMI. The fuel rod's smeared density is carefully chosen so that gap closure and porosity interconnection occur at roughly the same time, effectively ending swelling due to gaseous fission products as they are released and limiting FCMI [43]. This feature prevents stress buildup that might otherwise contribute to cladding rupture at low burnup. Because the fuel is notably more pliant than the cladding under these conditions, radial constraints on the fuel from the cladding may force fuel to swell in the axial dimension, driving further fuel elongation via thermal and irradiation creep; however, it is also possible that fuel-cladding contact provides frictional resistance against fuel elongation. The risks to the cladding associated with FCMI increase with burnup due to the accumulation of solid fission products and corresponding reduction in fuel porosity.

Low conductivity fission gases and porosity degrade heat transport through the fuel. Interconnected pores also provide pathways for high conductivity liquid sodium to enter the fuel from the gap, but questions remain about when sodium infiltration occurs and how deeply the sodium penetrates the fuel. Sodium infiltration is particularly difficult to characterize because many post-irradiation examination (PIE) techniques disrupt the fuel's sodium content. Studies based on the average fission gas and sodium contents of irradiated fuels suggest that their combined effects lower the effective thermal conductivity of the fuel, thus increasing fuel temperature [40]. Fortunately, other studies have shown that the magnitudes of these behaviors' effects on fuel temperature are much smaller than the margin to fuel melting [44]. Nonetheless, uncertainties associated with these behaviors and the temperature dependence of many material properties reduce our ability to predict fuel element response.

As is the case with fuel swelling, it is possible that differences in phase composition between binary and ternary fuels impact FCMI and fuel creep. Many of the correlations used to describe the behavior of metallic fuels were based on samples from a limited number of alloy compositions fabricated using different methods and having different irradiation histories [45]. The limited coverage of fuel composition effects and confounding of results from other uncharacterized parameters are likely to impact the accuracy and reliability of predictions obtained from hand calculations and fuel performance codes.

Current candidate cladding materials-HT-9, D9, and SS316 - are susceptible to thermal and irradiation creep and irradiation-induced swelling in varying degrees. The alloys also vary in strength and in their susceptibility to irradiation hardening from accumulation of irradiation-induced defects, radiation-induced segregation, and formation of secondary precipitates [46]. Of these materials, HT-9, a ferritic-martensitic steel, exhibits significantly less void swelling than austenitic alloys SS316 and D9 when subjected to high fast neutron fluxes at SFR-relevant temperatures [25], [47]. Correlations describing these swelling, creep, and creep-rupture behaviors can be used to predict cladding performance and to inform the establishment of deformation and cladding failure probability limits. 
The thermal and irradiation creep contributions are characterized by comparing experiments involving pressurized tubes at various pressure loadings, temperatures, and neutron fluxes. The magnitudes of the two contributions vary axially with fuel rod conditions. Thermal creep is more pronounced near the top of the fuel, where the temperature is highest. Irradiation creep is more prevalent near the fuel midplane, where the fast neutron flux is highest, and it is generally less of a performance concern. Depending on materials and operating conditions, these two contributions can be observed as multiple, often convoluted peaks in cladding profilometry data [48].

As noted in previous sections, mechanical contact between the fuel and cladding also enables FCCI [34]. The austenitic cladding materials considered here are susceptible to Ni depletion via FCCI, and HT-9 is susceptible to $\mathrm{C}$ depletion. These diffusive processes effectively thin the cladding through formation of wastage layers, which are conservatively assumed to be strengthless [47]. Lanthanide diffusion into the cladding can also form a brittle wastage layer, further reducing the margin to cladding rupture. Diffusion of $\mathrm{Fe}$ into the fuel lowers the solidus temperature of the affected fuel region and the associated margin to melting, increasing the risk of eutectic liquefaction [49]. FCCI is often observed near the top of the fuel slug, where high temperatures enhance interdiffusion.

As described in previous sections, multiple crystalline phases are stable in metallic fuels at room temperature and during normal operation. Temperature and chemical potential gradients between these regions with different phase compositions drive redistribution of fuel constituents [50], [51]. Constituent redistribution impacts the phase composition of the fuel and therefore its local melting temperature and other thermomechanical properties. Currently, the majority of property and behavior correlations available for metallic fuels are expressed in terms of bulk constituent composition, temperature, and/or burnup.

\section{CODE REQUIREMENTS}

This section defines technical and programmatic/logistical requirements for a metallic fuel performance code. It is helpful to distinguish between (1) a code's capabilities (the basis of technical requirements) and (2) the characteristics required for the code to be useful for a particular application (the basis of logistical/programmatic requirements). While the needs of each project and program will differ, these requirements should be generally applicable for codes intended for evaluation of new metallic fuel designs based on IFR-era designs. Specifically, these requirements are intended to support (1) U-Pu- $\mathrm{Zr}$ fuel alloys with Pu contents between 0 and 20\%, (2) ferritic-martensitic HT-9, austenitic D9, and austenitic SS316 cladding alloys, (3) fuel element geometries with smear densities of approximately $75 \%$, and (4) fuel elements that utilize a liquid sodium bond.

\subsection{TECHNICAL REQUIREMENTS}

Technical code requirements can be further divided into (1) behaviors and parameters to be modeled by a code and (2) how those models should be implemented and solved. The former category relates closely to earlier discussions involving design criteria and fuel performance. The latter category involves aspects of code architecture that handle transient or steady-state calculations and factors that impact the usefulness of predictions such as resolution and accuracy. Each of these considerations is described further below; these discussions are used to inform more formal technical requirements.

\subsubsection{Behaviors and Parameters to be Modeled by a Code}

To assess whether a fuel design can satisfy the design criteria, a fuel performance code should be able to calculate (1) fuel and cladding temperature, (2) fuel and cladding strain due to thermal expansion, irradiation-induced swelling, thermal creep, and irradiation creep, and (3) cladding stress due to internal 
fission gas pressure and FCMI, with consideration of cladding wastage. These calculations require models for heat generation and conduction, thermal expansion, elasticity, fuel-cladding contact, gaseous and solid swelling in the fuel, porosity formation and evolution in the fuel, FCMI, FGR, irradiation creep in the fuel and cladding, irradiation-induced swelling and embrittlement in the cladding, and FCCI. Models for constituent redistribution would also help with the initial correlation of metallic fuel properties and behaviors to local phase and constituent compositions rather than bulk constituent composition. Similarly, models that predict cladding failure probability would aid in assessment of margin to cladding breach.

The ideal fuel performance code would include a full set of correlations and models for all fuel and cladding material properties and behaviors. Unfortunately, the technical complexity of developing such a code and the limited availability of fundamental property data for some fuel element materials make this task unrealistic at this time [38]. However, engineering judgement can be used to define minimum requirements and additional features as realistic and achievable goals for the near term while ensuring that codes provide useful predictions. Because the codes may sometimes be based on sparse experimental data and/or unrealistic assumptions and simplifications, it is very important that the implications of known shortcomings be fully explored and documented. Benchmarking studies must be conducted to evaluate code accuracy and precision, and tools like uncertainty quantification should be applied to characterize uncertainties in code predictions and the sensitivity of code results to those uncertainties.

\subsubsection{Model Implementation and Solution}

Existing codes offer various levels of dimensionality ranging from 1.5 to $3 \mathrm{D}$. In a typical 1.5D approach, several radial 1D simulations are conducted at different axial heights. Limited coupling between the axialspecific simulations is achieved through axial relations and/or boundary conditions. This approach, which was widely adopted by early metallic fuel performance codes, takes advantage of the high aspect ratio of the problem to deliver predictions with minimal computational expense. The increasing availability of computational resources has recently made $2 \mathrm{D}$ axisymmetric simulations a popular choice. This approach allows for straightforward creation of multi-body fuel and cladding problems, permitting more flexible geometries, eliminating the need for axial relations, increasing the potential for visualization, and allowing for more intuitive definition of multidimensional phenomena such as mechanical contact and material deformation. 3D simulation techniques with the potential to more realistically model behaviors such as buckling and fuel relocation are also available, but these are used less frequently because the computational cost scales quickly with the number of problem dimensions. Both 1.5 and $2 \mathrm{D}$ approaches are expected to be appropriate for metallic fuel performance simulations in the near term.

Spatial discretization is also an important consideration in fuel performance simulations, which are normally performed using either the finite difference or finite element method. Each method has advantages and limitations, but both are expected to be sufficient for near-term modeling needs. Early fuel performance codes were developed to take advantage of the difference in time scales between normal operation and off-normal events. Separate code modules were sometimes written to model normal operation (often referred to as steady-state operation), during which behaviors of interest occur over periods ranging from days to years, and off-normal events (often referred to as transient operation), which occur in the range of fractions of a second to minutes [18], [36]. The two approaches are often optimized using different time integration schemes and solver options. Other codes utilize adaptive meshing and time-stepping schemes, as well as restart and recovery options, to seamlessly transition between the two time scales. This added flexibility makes these codes attractive for studies that involve simulating a wide variety of operating scenarios and conditions.

The ability to couple a fuel performance code to other codes is also an important consideration to improve the fidelity of the simulation. Coupling to engineering-scale codes such as a neutronics or thermal hydraulics code can help capture impactful multiphysics behaviors, whereas coupling to lower length 
scale codes can be used to supplement sparse fundamental property data with results from density functional theory, molecular dynamics, and phase-field simulations [52]. These techniques can help define material properties in the absence of experimental data, ensure consistency between boundary conditions and forcing functions, and more.

\subsubsection{Recommended Technical Requirements}

Selected technical code requirements based on these discussions are summarized in Table 3 . The minimum requirements correspond to a code that could be used for trend analysis to inform design decisions. Such a code would include substantial simplifications and assumptions and would likely rely heavily on calibration. It could be confidently applied only to narrow ranges of materials, geometries, and operational conditions. Incorporation of one or more desired features would make the code more useful by enabling it to simulate increasingly more detailed and realistic phenomena. The requirements explicitly state which parameters and behavior indicators a fuel performance code should be able to calculate to predict the margins to fuel melting and cladding rupture. The necessary material properties and behavioral models are implied by the requirements. Guidance related to problem dimensionality, handling of steadystate and transient operations, and coupling capabilities is also included in Table 3.

Table 3. Summary of selected technical code requirements

\begin{tabular}{|c|c|c|}
\hline Code capability & Minimum requirement & Additional desired features \\
\hline Calculate fuel temperature & Spatially resolved & \\
\hline Calculate cladding temperature & Maximum temperature & Spatially resolved \\
\hline Calculate coolant temperature & Along fuel element length & Axial and azimuthal (polar) resolution \\
\hline $\begin{array}{l}\text { Calculate fuel strain due to: } \\
\text { - Thermal expansion } \\
\text { - Gaseous swelling } \\
\text { - Solid swelling } \\
\text { - Porosity closure } \\
\text { (hot pressing) } \\
\text { - Thermal creep } \\
\text { - Irradiation creep }\end{array}$ & Integral fuel strain & $\begin{array}{l}\text { Spatially resolved due to each individual } \\
\text { contribution }\end{array}$ \\
\hline $\begin{array}{l}\text { Calculate cladding strain due to: } \\
\text { - Thermal expansion } \\
\text { - Irradiation-induced swelling } \\
\text { - Thermal creep } \\
\text { - Irradiation creep }\end{array}$ & $\begin{array}{l}\text { Maximum total radial } \\
\text { strain }\end{array}$ & $\begin{array}{l}\text { Spatially resolved due to each individual } \\
\text { contribution }\end{array}$ \\
\hline $\begin{array}{l}\text { Calculate cladding stress due to: } \\
\text { - Internal fission gas pressure } \\
\text { - FCMI }\end{array}$ & Maximum hoop stress & Spatially resolved stress state \\
\hline $\begin{array}{l}\text { Calculate wastage region } \\
\text { thickness }\end{array}$ & $\begin{array}{l}\text { Maximum cladding } \\
\text { penetration }\end{array}$ & $\begin{array}{l}\text { Spatially resolved due to the individual } \\
\text { contributions of FCCI and eutectic liquefaction }\end{array}$ \\
\hline $\begin{array}{l}\text { Calculate cladding failure } \\
\text { probability }\end{array}$ & & Spatially resolved failure behavior \\
\hline Model constituent redistribution & & $\begin{array}{l}\text { Spatially resolved phase and constituent } \\
\text { compositions }\end{array}$ \\
\hline Address problem dimensionality & $1.5 \mathrm{D}$ & $2 \mathrm{D}$ and $3 \mathrm{D}$ \\
\hline $\begin{array}{l}\text { Provide steady-state and transient } \\
\text { capabilities }\end{array}$ & Separate & Combined \\
\hline Provide coupling capabilities & & $\begin{array}{l}\text { Compatible with lower length scale, thermal } \\
\text { hydraulics, neutronics, and systems codes }\end{array}$ \\
\hline
\end{tabular}




\subsection{PROGRAMMATIC AND LOGISTICAL REQUIREMENTS}

The technical code requirements introduced in the previous section were motivated primarily by the need to simulate physics and material behavior during operation. Further discussion is necessary to outline programmatic and logistical code requirements, which help to ensure that a fuel performance code can provide useful information in practical situations. Programmatic and logistical code requirements can be further divided into requirements that relate to (1) accuracy and uncertainty, (2) computational performance, and (3) accessibility and ease of use. Each of these categories is detailed further below.

\subsubsection{Accuracy and Uncertainty}

The utility of a fuel performance code to a particular project or program may be limited unless it can provide sufficiently accurate predictions with acceptable levels of uncertainty. The needs of each project and program will differ, so quantitative requirements for these metrics are not prescribed in this report. Instead, the focus here is on more general considerations such as definition of what constitutes acceptable estimates of accuracy and uncertainty, as well as the determination of how these metrics should be evaluated, how frequently, and by whom? Determination of what constitutes acceptable estimates of accuracy and uncertainty depends on the project or program. The confidence in and utility of a code's predictions generally increases with the number of successful benchmarking studies and the availability of quantitative (as opposed to qualitative) uncertainty results.

The accuracy of a code can be evaluated using benchmarks, which involve simulating irradiation experiments and comparing code predictions directly to PIE data. Benchmark simulations require detailed heat generation and coolant flow data to properly define boundary conditions and forcing functions. The limited availability and resolution of these data define an upper limit on how well an irradiation experiment can be reproduced within the code. Often, simulations must be conducted in regions of the design space for which there are no experimental data. Comparisons between multiple, independent fuel performance codes can be used in these cases. Agreement between the codes increases the confidence in their predictions, but benchmarks are typically preferred. Code comparisons also allow for comparison of predictions for quantities that cannot be measured using PIE.

Uncertainties can be evaluated using methods such as forward uncertainty quantification, in which simulations are conducted using input parameters drawn from statistical distributions to examine the overall effects on a code's predictions [53]. This technique can be applied to quantitatively estimate the relationship between variations in parameters like manufacturing tolerances and code predictions such as peak fuel temperature.

Establishing benchmark problems is a crucial step toward gaining confidence in the predictive capabilities of the code. Operational and PIE data collected from IFR-era experiments involving different geometries, fuel and cladding materials, and irradiation conditions are available in online databases [54]. These data can be used to construct benchmarks that span large portions of the design space. A code with the flexibility to model multiple different designs could utilize more of the available historical data. This is particularly advantageous if the design of interest has only been subjected to limited testing or no testing at all. Demonstrating acceptable accuracy over a range of design parameters increases confidence in a code's ability to interpolate within that range.

It is usually not sufficient to test a single model or material property, because metallic fuel element irradiation behaviors are very tightly coupled. This makes benchmarks particularly important, as they offer a means to test integral effects. Ideally, a suite of benchmarking studies would be conducted to evaluate all code revisions. Given that, it may be advantageous for developers to periodically release stable, vetted versions of the code. The entity performing the vetting may vary. Some projects and 
programs may leave this task to the code developers, whereas others may require researchers, engineers, regulators, or selected users to independently assess the code.

NRC's general design criteria require that quality standards and recordkeeping practices be established to support the design of any components important to safety. It is logical that a quality assurance program should be applied to the fuel performance codes that are used to inform fuel element design and that provide supplemental information for their safety bases. One such program is the American Society of Mechanical Engineers (ASME) Nuclear Quality Assurance-1 (NQA-1) certification [55]. NQA-1 offers guidance to help code developers establish quality programs appropriate for their codes and then provides a common standard against which to evaluate those programs. Compliance with standards like these further enhances confidence in fuel performance code predictions.

\subsubsection{Computational Performance}

Computational performance is another important consideration. Projects and programs may need to establish requirements for scalability, compatibility with different operating systems, and overall resource usage. These requirements may vary, depending on whether fuel performance simulations will be run on desktop machines or high-performance computing clusters, and whether the work will require extensive use of sensitivity analysis, uncertainty quantification, and/or model calibration. As mentioned above, the time and resources necessary to perform these calculations quickly increases with the spatial, temporal, and physical fidelity of the simulation.

\subsubsection{Accessibility and Ease of Use}

Code accessibility and ease of use are also important factors to consider. While some codes are widely available, access to others can be restricted due to export controls or inclusion of sensitive and/or proprietary information. The learning curve for fuel performance codes is often steep, so the availability of experienced users and/or training for new users are important considerations. Detailed, thorough, wellcited code documentation is a valuable tool for both new and experienced users. Codes with fewer configurable options are typically easier to use, but they do not offer the flexibility of more customizable codes. Some applications may require maintenance or modification of the code. In these cases, it may be advantageous to select a code implemented using a modern programming language and an object-oriented design. These features may make it easier to modify the code while observing quality assurance requirements.

Use of some codes may offer other advantages, such as compatibility with common file formats for input file generation, data processing, and visualization and compatibility with irradiation experiment and material property databases. Fuel performance codes also differ in their reliance on underlying libraries, which are used for finite element analysis, numerical solution of differential equations, and more. Use of codes that employ proprietary libraries may enhance quality and security, but this may require usage licenses and subscriptions at additional cost. Open-source libraries may be more flexible and cost effective, but they are less well controlled and could require additional quality assurance measures.

\subsubsection{Recommended Programmatic and Logistical Requirements}

It is difficult to define general programmatic and logistical code requirements because they depend on the specific needs of the project or program involved. Important considerations from this section are summarized in an easily referenced list below. These factors should be considered when selecting a fuel performance code, prioritizing further code development, establishing and maintaining quality programs, and compiling a code benchmarking plan: 
1. Acceptable levels of accuracy and uncertainty and definition of how these metrics must be evaluated, how frequently they must be evaluated, and by whom

2. Determination of how benchmarking, code comparisons, and uncertainty quantification will be employed to establish confidence in code predictions

3. Availability and acceptability of stable, vetted versions of the code for the proposed work, or in their absence, determination of how the above techniques will be applied to evaluate new code revisions

4. Definition of the quality assurance and documentation standards to be observed

5. Requirements for computational performance, scalability, and operating system compatibility

6. Controls or restrictions necessary to protect sensitive and/or proprietary information, and applicable export controls, if any

7. The training and documentation available to users and the time needed for users to become proficient in using the code

8. Identification of the necessary code modifications and assessment of how difficult they will be to implement while conforming to established quality protocols

9. Code compatibility with the preferred data processing and visualization tools and with the databases to be used in the work

10. Requirements associated with the cost, quality, security, and flexibility of underlying libraries, if any

\section{CONCLUSIONS}

Metallic nuclear fuels have been proposed for use in several emerging applications, and a number of codes have been developed to model their performance. The results from benchmark problems available for these codes in the open literature seem promising, but documentation of the codes and access to the codes themselves are generally limited. While fuel qualification will ultimately require irradiation and monitoring of lead test assemblies, use of fuel performance codes can lessen the uncertainties associated with new fuel designs by quantifying uncertainties and estimating margins to failure ahead of time. As such, fuel designs for new reactor designs will likely rely on a combination of legacy designs and safety and performance analyses obtained from fuel performance codes.

This document examines functional and operational requirements, as well as the design criteria applied to EBR-II Mark-V and Mark-VA driver fuel. This work also provides an overview of metallic fuel thermomechanical responses and irradiation behaviors in order to identify general expectations for fuel performance codes. Requirements are defined for a metallic fuel performance code, focusing on designs that utilize U-Pu-Zr fuel alloys with Pu contents between 0 and 20\%; HT-9, D9, and SS316 claddings; smeared densities of about $75 \%$; and a liquid sodium bond. A number of minimum technical requirements and additional desired features for fuel performance codes are listed, as are programmatic and logistical considerations for fuel performance code development, selection, and use.

These requirements will inform development of a benchmarking plan for the VTR project, which is planned for the near future. In the benchmarking plan, the selected metallic fuel performance code will be evaluated against the technical code requirements to identify potential shortcomings and to inform recommendations for further development. The logistical and programmatic code requirements will 
continue to be refined as necessary and appropriate in collaboration with VTR leadership, members of the VTR quality team, and others. 


\section{REFERENCES}

[1] J. Vujic, R. M. Bergmann, R. Skoda, and M. Miletic, "Small Modular Reactors: Simpler, Safer, Cheaper?," Energy, vol. 45, no. 1, pp. 288-295, 2012, doi: 10.1016/j.energy.2012.01.078.

[2] A. M. Yacout and M. C. Billone, "Pre-Licensing Evaluation of Legacy SFR Metallic Fuel Data," ANL-ART-76, Argonne National Laboratory, 2017.

[3] "Pilot Application for DG-1353 - OKLO-2018-R10-P," Oklo, Inc. Sunnyvale, California, 2018.

[4] "Versatile Test Reactor" US Department of Energy Office of Nuclear Energy, https://www.energy.gov/ne/nuclear-reactor-technologies/versatile-test-reactor (accessed Sep. 15, 2020).

[5] Y.-I. Chang, "Technical Rationale for Metal Fuel in Fast Reactors," Nucl. Eng. Technol., vol. 39, no. 3, pp. 161-170, 2007, doi: 10.5516/net.2007.39.3.161.

[6] D. Petti et al., "A Summary of the Department of Energy's Advanced Demonstration and Test Reactor Options Study," Nucl. Technol., vol. 199, no. 2, pp. 111-128, 2017, doi: 10.1080/00295450.2017.1336029.

[7] Y. I. Chang, L. C. Walters, J. J. Laidler, D. R. Pedersen, D. C. Wade, and M. J. Lineberry, "Integral Fast Reactor Program Annual Progress Report FY 1994 - ANL-IFR-246," Argonne National Laboratory, 1994.

[8] R. Seidel et al., "A Decade of Advances in Metallic Fuel," 1990.

[9] R. G. Pahl, D. L. Porter, D. C. Crawford, and L. C. Walters, "Irradiation Behavior of Metallic Fast Reactor Fuels," J. Nucl. Mater., vol. 188, no. C, pp. 3-9, 1992, doi: 10.1016/0022-3115(92)90447S.

[10] D. E. Burkes, R. S. Fielding, D. L. Porter, D. C. Crawford, and M. K. Meyer, “A US Perspective on Fast Reactor Fuel Fabrication Technology and Experience Part I: Metal Fuels and Assembly Design," J. Nucl. Mater., vol. 389, no. 3, pp. 458-469, 2009, doi: 10.1016/j.jnucmat.2009.02.035.

[11] W. J. Carmack et al., "Metallic Fuels for Advanced Reactors," J. Nucl. Mater., vol. 392, no. 2, pp. 139-150, 2009, doi: 10.1016/j.jnucmat.2009.03.007.

[12] M. Billone, Y. Liu, E. Gruber, T. Hughes, and J. Kramer, "Status of Fuel Element Modeling Codes for Metallic Fuels," in Reliable Fuels for Liquid Metal Reactors, 1986, pp. 77-92.

[13] A. M. Yacout and M. C. Billone, "Current Status of the LIFE Fast Reactors Fuel Performance Codes," IAEA-CN-199; IAEA-CN-199/435, 2013.

[14] T. Kobayashi et al., "Development of the SESAME Metallic Fuel Performance Code," Nucl. Technol., vol. 89, no. 2, 1990, doi: 10.13182/NT90-A34345.

[15] T. Ogata and T. Yokoo, "Development and Validation of ALFUS: an Irradiation Behavior Analysis Code for Metallic Fast Reactor Fuels," Nucl. Technol., vol. 128, no. 1, pp. 113-123, 1999, doi: 10.13182/NT99-A3018.

[16] W. Hwang, C. Nam, T. S. Byun, and Y. C. Kim, "MACSIS: A Metallic Fuel Performance Analysis Code for Simulating In-reactor Behavior under Steady-State Conditions," Nucl. Technol., vol. 123, no. 2, pp. 130-141, 1998, doi: 10.13182/NT98-A2887.

[17] A. Karahan and J. Buongiorno, "A New Code for Predicting the Thermo-Mechanical and Irradiation Behavior of Metallic Fuels in Sodium Fast Reactors," J. Nucl. Mater., vol. 396, no. 23, pp. 283-293, 2010, doi: 10.1016/j.jnucmat.2009.11.022.

[18] A. Prudil, B. J. Lewis, P. K. Chan, and J. J. Baschuk, "Development and Testing of the FAST Fuel Performance Code: Normal Operating Conditions (Part 1)," Nucl. Eng. Des., vol. 282, pp. 158168, 2015, doi: 10.1016/j.nucengdes.2014.09.036.

[19] J. D. Hales et al., "BISON Theory Manual: the Equations behind Nuclear Fuel Analysis - BISON Release 1.3,” INL/EXT-13-29930, Idaho Falls, Idaho, 2016. doi: 10.2172/1107264.

[20] S. R. Novascone, A. Casagranda, P. G. Medvedev, C. Matthews, and A. X. Zabriskie, "Summary and Assessment of Metallic Fuel Capabilities in Bison, INL/EXT-18-51399," Idaho Falls, Idaho, 2018. 
[21] A. Karahan, "Development of Advanced In-Pin Metallic Fuel Performance Models for SAS4A," in Transactions of the American Nuclear Society, 2014, vol. 110, pp. 912-2014.

[22] A. Karahan, A. Tentner, and S. Kang, "Validation of Advanced In-Pin Metallic Fuel Models of SAS4A," in Transactions of the American Nuclear Society, 2016, vol. 115, pp. 1585-1588.

[23] A. M. Tentner, A. Karahan, and S. H. Kang, "Overview of the SAS4A Metallic Fuel Models and Extended Analysis of a Postulated Severe Accident in the Prototype Gen-IV Sodium-Cooled Fast Reactor," Nucl. Technol., vol. 206, no. 2, pp. 242-254, 2020, doi: 10.1080/00295450.2019.1636589.

[24] D. C. Crawford, L. Steven, and J. J. Powers, "VTR Startup Fuel Paper for NFSM," INL/EXT-1844673, Idaho Falls, Idaho, 2018.

[25] J. H. Kittel, B. R. Frost, J. P. Mustelier, K. Q. Bagley, G. C. Crittenden, and J. Van Dievoet, "History of Fast Reactor Fuel Development," J. Nucl. Mater., vol. 204, pp. 1-13, 1993, doi: 10.1016/0022-3115(93)90193-3.

[26] D. C. Crawford, D. L. Porter, and S. L. Hayes, "Fuels for Sodium-Cooled Fast Reactors: US Perspective," J. Nucl. Mater., vol. 371, no. 1-3, pp. 202-231, 2007, doi:

10.1016/j.jnucmat.2007.05.010.

[27] T. H. Bauer, A. E. Wright, W. R. Robinson, J. W. Holland, and E. A. Rhodes, "Behavior of Modern Metallic Fuel in Treat Transient Overpower Tests," Nucl. Technol., vol. 92, no. 3, pp. 325-352, 1990, doi: 10.13182/NT92-325.

[28] Y. Miao, N. Stauff, A. Oaks, A. M. Yacout, and T. K. Kim, "Fuel Performance Evaluation of Annular Metallic Fuels for an Advanced Fast Reactor Concept," Nucl. Eng. Des., vol. 352, no. June, 2019, doi: 10.1016/j.nucengdes.2019.110157.

[29] J. H. Kim et al., "Performance of a Diffusion Barrier under a Fuel-Clad Chemical Interaction (FCCI)," J. Nucl. Mater., vol. 394, no. 2-3, pp. 144-150, 2009, doi: 10.1016/j.jnucmat.2009.08.018.

[30] General Design Criteria for Nuclear Power Plants. US: Nuclear Regulatory Commission, 2012, pp. 969-977.

[31] "Guidance for Developing Principal Design Criteria for Non-Light Water Reactors," RG 1.232 Rev 0, 2018.

[32] L. Briggs, Y. Chang, and D. Hill, "Safety Analysis and Technical Basis for Establshing an Interim Burnup Limit for Mark-V and Mark-VA Fuel Subassemblies in EBR-II - ANL-NSE-1,” Argonne, Illinois, 1995.

[33] D. L. Porter and D. C. Crawford, "VTR Fuel Performance Design Basis, ” INL/LTD-19-56521, Idaho Falls, Idaho, 2020.

[34] C. Matthews, C. Unal, J. Galloway, D. D. Keiser, and S. L. Hayes, "Fuel-Cladding Chemical Interaction in U-Pu-Zr Metallic Fuels: A Critical Review," Nucl. Technol., vol. 198, no. 3, pp. 231-259, 2017, doi: 10.1080/00295450.2017.1323535.

[35] I. M. Hobbs and J. A. Charboneau, "Compressibility of Gas Mixtures Pertaining to Nuclear Fuel Rods," J. Phys. Commun., vol. 4, pp. 1-7, 2020, doi: 10.1088/2399-6528/abbba4.

[36] A. Prudil, B. J. Lewis, P. K. Chan, J. J. Baschuk, and D. Wowk, "Development and Testing of the FAST Fuel Performance Code: Transient Conditions (Part 2),” Nucl. Eng. Des., vol. 282, pp. 169 177, 2015, doi: 10.1016/j.nucengdes.2014.11.036.

[37] G. L. Hofman, L. C. Walters, and T. H. Bauer, "Metallic Fast Reactor Fuels," Prog. Nucl. Energy, vol. 31, no. 1/2, pp. 83-110, 1997.

[38] A. Aitkaliyeva, M. Tonks, J. Hirschhorn, J. Powers, I. Greenquist, and B. Beeler, "Research Needs for Uranium-Zirconium- Based Metallic Fuels," INL/EXT-20-58719, Idaho Falls, Idaho, 2020.

[39] G. L. Hofman, R. G. Pahl, C. E. Lahm, and D. L. Porter, "Swelling Behavior of U-Pu-Zr Fuel," Metall. Trans. A, vol. 21, no. 2, pp. 517-528, 1990, doi: 10.1007/BF02671924.

[40] T. H. Bauer and J. W. Holland, "In-Pile Measurement of the Thermal Conductivity of Irradiated Metallic Fuel," Nucl. Technol., vol. 110, no. 3, pp. 407-421, 1995, doi: 10.13182/nt95-a35110.

[41] S. Hayes, D. Crawford, and R. Pahl, "Test Design Description and Postirradiation Examination of 
the HT9 advanced Driver Fuel Test (X430),” ANL-IFR-225, Argonne, Illinois, 1994.

[42] R. G. Pahl, D. L. Porter, C. E. Lahm, and G. L. Hofman, "Experimental Studies of U-Pu-Zr Fast Reactor Fuel Pins in the Experimental Breeder Reactor-II," Metall. Trans. A, Phys. Metall. Mater. Sci., vol. 21 A, no. 7, pp. 1863-1870, 1990, doi: 10.1007/BF02647233.

[43] G. Fenske, J. Emerson, F. Savoie, and E. Johanson, "Fission Gas Retention and Axial Expansion of Irradiated Metallic Fuel,” ANL-IFR-45, Argonne, Illinois, 1986.

[44] A. M. Yacout, W. S. Yang, G. L. Hofman, and Y. Orechwa, "Average Irradiation Temperature for the ANALYsis of In-Pile Integral Measurements," Nucl. Technol., vol. 115, no. 1, pp. 61-72, 1996, doi: 10.13182/NT96-A35275.

[45] G. Hofman et al., "Metallic Fuels Handbook," ANL-NSE-3, Argonne, Illinois, 1989.

[46] Y. Chen, "Irradiation Effects of HT-9 Martensitic Steel," Nucl. Eng. Technol., vol. 45, no. 3, pp. 311-322, 2013, doi: 10.5516/NET.07.2013.706.

[47] R. G. Pahl, C. E. Lahm, and S. L. Hayes, "Performance of HT9 Clad Metallic Fuel at High Temperature," J. Nucl. Mater., vol. 204, no. C, pp. 141-147, 1993, doi: 10.1016/00223115(93)90210-P.

[48] W. J. Carmack, H. M. Chichester, D. L. Porter, and D. W. Wootan, "Metallography and Fuel Cladding Chemical Interaction in Fast Flux Test Facility Irradiated Metallic U-10Zr MFF-3 and MFF-5 Fuel Pins," J. Nucl. Mater., vol. 473, pp. 167-177, 2016, doi: 10.1016/j.jnucmat.2016.02.019.

[49] R. D. Mariani, D. L. Porter, T. P. O’Holleran, S. L. Hayes, and J. R. Kennedy, "Lanthanides in Metallic Nuclear Fuels: Their Behavior and Methods for Their Control," J. Nucl. Mater., vol. 419, no. 1-3, pp. 263-271, 2011, doi: 10.1016/j.jnucmat.2011.08.036.

[50] J. Hirschhorn, M. Tonks, A. Aitkaliyeva, and C. Adkins, "Reexamination of a U-Zr Diffusion Couple Experiment Using Quantitative Phase-Field Modeling and Sensitivity Analysis," J. Nucl. Mater., vol. 529, p. 151929, 2020, doi: 10.1016/j.jnucmat.2019.151929.

[51] J. Galloway, C. Unal, N. Carlson, D. Porter, and S. Hayes, "Modeling Constituent Redistribution in U-Pu-Zr Metallic Fuel Using the Advanced Fuel Performance Code BISON," Nucl. Eng. Des., vol. 286, pp. 1-17, 2015, doi: 10.1016/j.nucengdes.2015.01.014.

[52] D. R. Gaston et al., "Physics-Based Multiscale Coupling for Full Core Nuclear Reactor Simulation," Ann. Nucl. Energy, vol. 84, pp. 45-54, 2015, doi: 10.1016/j.anucene.2014.09.060.

[53] G. Pastore et al., "Uncertainty and Sensitivity Analysis of Fission Gas Behavior in EngineeringScale Fuel Modeling," J. Nucl. Mater., vol. 456, pp. 398-408, 2015, doi: 10.1016/j.jnucmat.2014.09.077.

[54] M. Yacout, A. Oaks, W. Mohamed, and K. Mo, "FIPD: EBR-II Fuels Irradiation \& Physics Database," ANL-ART-124, Argonne, Illinois, 2017.

[55] “ASME NQA-1 Certification Program - Requirements for ASME NQA-1 Certification," New York, New York, 2014. 